Melissa Orzechowski XAVIER ${ }^{1}$

Isabel Martins MADRID ${ }^{1}$ Marlete Brum CLEFF ${ }^{2}$

Ângela Leitzke CABANA ${ }^{1}$ Rodolfo Pinho da SILVA $\mathrm{FILHO}^{3}$

Mário Carlos Araújo MEIRELES ${ }^{1}$

Correspondência para:

Melissa Orzechowski Xavier, Rua Paul Harris, 537. Areal, 96077-200, Pelotas, RS - Brasil.E-mail:melissaxavier@bol.com.br. Telefones: (53)3275-7496; (53)3228-9620; (53)91229266.

Recebido para publicação: 17/04/2007 Aprovado para publicação: 13/12/2007

\title{
Contaminação do ar por Aspergillus em ambiente de reabilitação de animais marinhos
}

\author{
1 - Departamento de Veterinária Preventiva da Faculdade de Veterinária da \\ Universidade Federal de Pelotas, Pelotas-RS \\ 2 - Programa de Pós-Graduação em Ciências Veterinárias da Faculdade de \\ Veterinária da Universidade Federal do Rio Grande do Sul, Porto Alegre-RS \\ 3 - Médico Veterinário do Centro de Recuperação de Animais Marinhos de Rio \\ Grande da Fundação Universidade Federal de Rio Grande, Rio Grande-RS
}

\section{Resumo}

Espécies fúngicas do gênero Aspergillus são frequentemente associadas com alta mortalidade de aves marinhas em cativeiro. Tendo em vista que a aspergilose geralmente é adquirida pela inalação dos propágulos fúngicos presentes no ar, o estudo objetivou avaliar a qualidade do ar quanto às espécies de Aspergillus, das instalações internas de um centro de reabilitação de animais marinhos que frequentemente recebe pingüins, gaivotas, albatrozes e petréis acometidos por alguma moléstia. Oitenta e um dias de colheitas foram realizados distribuídos em um período de aproximadamente dois anos, através da exposição de placas de Petri contendo Agar Sabouraud dextrose acrescido de cloranfenicol no ambiente, as quais foram posteriormente incubadas a $25^{\circ} \mathrm{C}$. As colônias identificadas como pertencentes ao gênero Aspergillus, foram classificadas quanto à espécie através da avaliação macro e micro morfológica associada a uma chave de identificação. Foram obtidos 43 isolados classificados em sete espécies distintas, sendo $A$. fumigatus a predominante correspondendo a $27,9 \%$, seguida de $A$. niger, $A$. flavus e outras quatro espécies de Aspergillus sp., demonstrando que as aves marinhas estão expostas a espécies fúngicas com potencial patogênico, o que enfatiza a necessidade de um controle microbiológico no ambiente onde são mantidos os animais em cativeiro.

\section{Introdução}

Os microrganismos do gênero Aspergillus estão distribuídos mundialmente e são considerados os fungos filamentosos anemófilos de maior importância quanto à contaminação do ar de recintos fechados. Este gênero na forma anamorfa pertence à divisão Eucomycota, subdivisão Deuteromicotina, classe Hyphomycetes, ordem Moniliales, família Moniliaceae e apresenta mais de cem espécies, as quais são identificadas conforme características morfológicas, sendo atualmente divididas em seis subgêneros, Aspergillus, Fumigati, Ornati, Clavati, Nidulantes e Circumdati, com uma ou mais seções. ${ }^{1,2}$
Todas as espécies de Aspergillus formam colônias filamentosas de diferentes características que microscopicamente apresentam hifas septadas de aproximadamente $4 \mathrm{~mm}$ de diâmetro, e estruturas de frutificação típica formada por célula-pé, conidióforo, vesícula, métula e/ou fiálide que promovem a reprodução assexuada do fungo através da produção de fialoconídios. Algumas espécies de Aspergillus apresentam a forma sexuada caracterizada pela presença de cleistotécios, ascos e ascósporos. Nestes casos, o fungo é classificado como teleomorfo e pertencente a um dos oito gêneros Emericella, Eurotium, Chaetosartorya, Neosartorya, Petromyces, Hemicarpenteles, Sclerocleista ou Fennellia. ${ }^{1,2,3}$ 
Cerca de 20 espécies do gênero Aspergillus são consideradas patogênicas, com capacidade de causar a aspergilose, doença freqüentemente associada à alta mortalidade de pingüins e outras aves marinhas em cativeiro. Esta micose geralmente é adquirida por inalação dos propágulos fúngicos presentes no ambiente, podendo caracterizar uma infecção nosocomial. 4,5,6,7,8,9,10 A suscetibilidade das aves a esta micose é determinada, principalmente, por peculiaridades do seu trato respiratório, como ausência de diafragma e presença de sacos aéreos que proporcionam um excelente local de colonização fúngica, com ótimas condições de temperatura e oxigênio e pouca vascularização. ${ }^{11}$

Em centros de recuperação de animais marinhos os quais recebem constantemente aves para reabilitação, como gaivotas, pingüins, albatrozes e petréis, a predisposição à aspergilose é ainda maior, à medida que frequentemente estas aves são recebidas com alguma injuria primária, e submetidas ao "stress" do cativeiro, o que agrava sua imunossupressão. ${ }^{6,12,13} \mathrm{Em}$ vista desta realidade, o trabalho teve como objetivo avaliar a qualidade do ar quanto à presença de espécies de Aspergillus no ambiente interno de reabilitação de um centro de recuperação de animais marinhos, localizado na cidade de Rio Grande, RS, Brasil.

\section{Material e Método}

A avaliação da presença de espécies de Aspergillus foi realizada por um período de aproximadamente dois anos, onde foram colhidas amostras das instalações internas do Centro de Recuperação de Animais Marinhos (CRAM) da Fundação Universidade Federal de Rio Grande e realizadas as identificações taxonômicas dos microrganismos no Setor de Micologia da Faculdade de Veterinária da Universidade Federal de Pelotas (FV-UFPel), com confirmação no Departamento de Micologia da Fundação Oswaldo Cruz.

$\mathrm{O}$ ambiente estudado apresentava
$12 \mathrm{~m}$ de comprimento, $4 \mathrm{~m}$ de largura e $4 \mathrm{~m}$ de altura, com paredes azulejadas e ventilação natural feita por meio de dois portões de $2 \times 2 \mathrm{~m}$ localizados nas duas extremidades da sala de cativeiro. A limpeza era realizada como prática constante e rotineira no CRAM mantendo o ambiente higienizado, embora no período noturno ocorresse acúmulo de excreções dos animais, a qual era eliminada no primeiro horário da manhã.

As colheitas das amostras foram realizadas a cada 10 dias através da técnica de sedimentação. As placas de Petri contendo Difco-Agar Sabouraud dextrose acrescido de cloranfenicol $(50 \mathrm{mg} / \mathrm{L})$ foram abertas por 15 minutos em três pontos distintos do ambiente de cativeiro interno a uma distância de aproximadamente $1,5 \mathrm{~m}$ do solo, sendo posteriormente encaminhadas ao Setor de Micologia (FV-UFPel).

As placas foram incubadas à $25^{\circ} \mathrm{C}$ por até sete dias com observação diária do crescimento fúngico. Depois de decorrido este período todas as colônias filamentosas foram submetidas a exame direto com Lactofenol azul de algodão, e observadas ao microscópio ótico em um aumento de 100 e 400X. Das colônias identificadas como pertencentes ao gênero Aspergillus foram realizados repiques em tubos de ensaio contendo Difco-Agar Batata (PDA) para obtenção da cultura pura.

Todas as amostras foram armazenadas na micoteca em tubos de ensaio contendo PDA acrescido de óleo mineral estéril, e sob refrigeração $\left(4^{\circ} \mathrm{C}\right) \mathrm{em}$ frascos fechados contendo $10 \mathrm{ml}$ de solução salina $0,9 \%$ tamponada estéril (PBS).

A classificação das espécies de Aspergillus foi realizada conforme protocolo e chave de identificação propostos por $\mathrm{Klich}^{2}$, e confirmada pela descrição de Raper e Fennell ${ }^{3}$. Para isso, foram utilizados quatro meios de cultivo diferentes (Difco-Agar Malte, Difco-Agar Czapek, Difco-Agar Czapek acrescido de extrato de levedura, Difco-Agar Czapek acrescido de extrato de levedura e $20 \%$ de sacarose), e sete dias de incubação em temperaturas de $37^{\circ} \mathrm{C}$ e/ou $25^{\circ} \mathrm{C}$. Após este período foram avaliadas 
características macro morfológicas como coloração do anverso e reverso, diâmetro, presença de esclerócios, exsudato e/ou pigmento solúvel das colônias nos quatro meios semeados. $\mathrm{O}$ cultivo em lâmina foi realizado para avaliação da micromorfologia do fungo observando características do conidióforo, vesícula, métula e/ou fiálide, conídios, presença de aleuroconídios, cleistotécios, ascos, ascósporos e/ou células estéreis (células de Hülle) circundando os cleistotécios.

\section{Resultados e Discussão}

Durante o experimento foram efetuados 81 dias de colheitas, dos quais 27 $(33,3 \%)$ foram positivos para o isolamento de uma ou mais espécies de fungos do gênero Aspergillus, obtendo-se um total de 43 isolados de Aspergillus spp.

Dos 43 isolados, vinte e dois pertenciam ao subgênero Circumdati, apresentando características como vesícula globosa e fértil em toda superfície, disposta de forma radiada, com métula frequentemente presente (Figura 1A). Doze isolados apresentaram conidióforos lisos, vesículas piriformes a clavadas, ausência de métula e conídios verde-acizentados a azulacizentados, características referentes ao subgênero Fumigati (Figura 1B). Seis isolados do subgênero Nidulantes se caracterizaram por conidióforo liso, vesícula subglobosa a clavadas férteis na metade superior, com a presença de métulas de distribuição colunar ou radiada e alguns com aleuroconídios (Figura 1C). E três isolados foram identificados como pertencentes ao subgênero Aspergillus, caracterizado por conidióforo de paredes lisas, vesículas subglobosas com fiálides na porção superior, ausência de métula, conídios geralmente em tons de verde, e presença de cleistotécios com ascos e ascósporos (Figura 1D).

Quanto à classificação por espécies, do total de isolados de Aspergillus spp., 12 foram identificados como pertencentes ao subgênero Fumigati, seção Fumigati, espécie A. fumigatus; 11 ao subgênero Circumdati, seção Nigri, espécie $A$. niger; sete ao subgênero Circumdati, seção Flavi, espécie $A$. flavus; quatro ao subgênero Circumdati, seção Circumdati, espécie $A$. candidus; três ao subgênero Nidulantes, seção Terrei, espécie $A$.

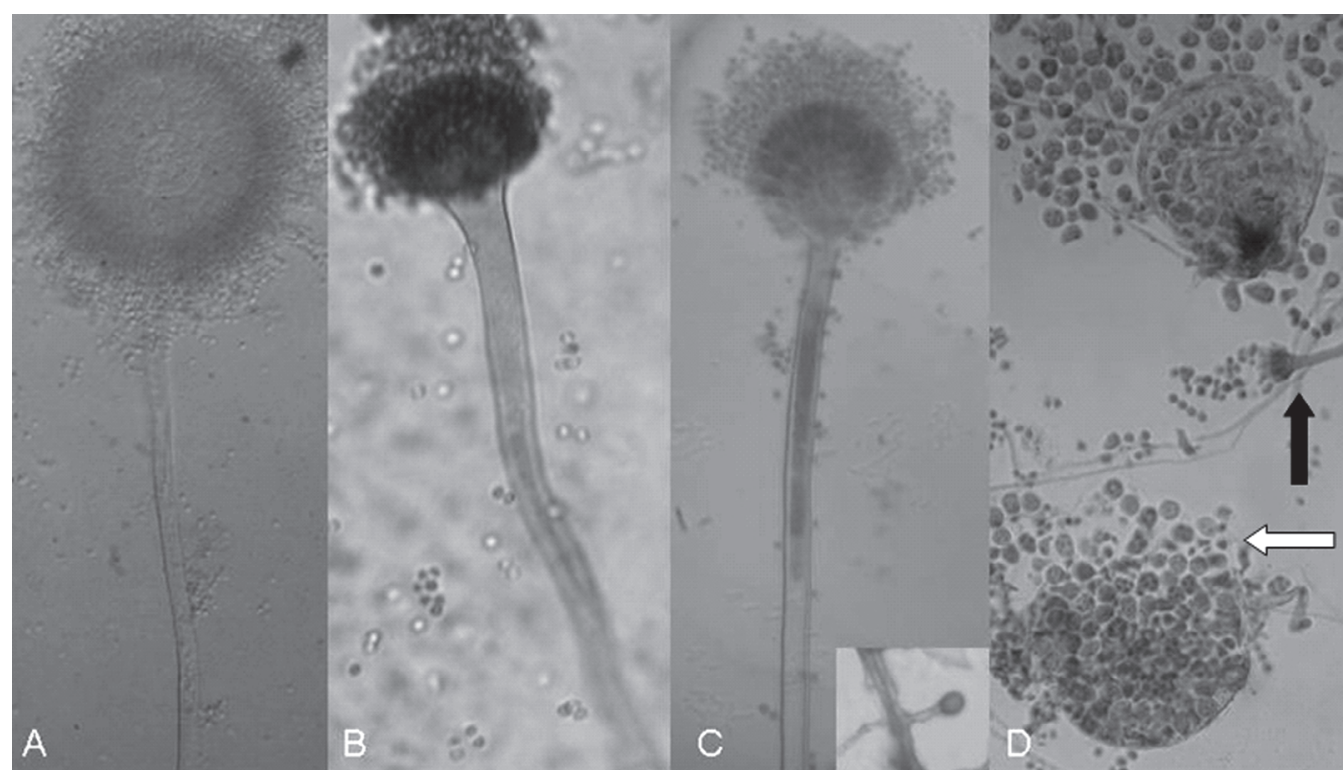

Figura 1 - Estruturas de reprodução de diferentes subgêneros de fungos Aspergillus. [A] Subgênero Circumdati; [B] Subgênero Fumigati; [C] Subgênero Nidulantes, detalhe dos aleuroconídios encontrados na espécie A. terreus; [D] Subgênero Aspergillus, seta preta e branca demonstrando, respectivamente, estrutura de reprodução assexuada e sexuada 
terreus; três ao subgênero Nidulantes, seção Versicolores, espécie $A$. versicolor, e três ao subgênero Aspergillus, seção Aspergillus, espécie teleomorfa Eurotium chevalieri (Tabela 1).

Diversos estudos da qualidade do ar de ambientes internos têm sido realizados, porém muitos enfocam a classificação taxonômica dos microrganismos somente até gênero fúngico, sem identificação de espécie. Nestes trabalhos o gênero Aspergillus se destaca como um dos principais fungos anemófilos presentes em ambientes internos $14,15,16,17$, o qual foi encontrado em $33,3 \%$ das amostras do presente estudo.

Quanto às espécies de Aspergillus, as três principais isoladas foram previamente documentadas como as mais freqüentes em ambientes hospitalares por Leenders et al. ${ }^{18}$ na Holanda, e Panagopoulou et al. ${ }^{19}$ na Grécia. Neste último trabalho, a espécie mais prevalente foi o $A$. niger (39,2\%) seguido do A. flavus $(17,5 \%)$ e $A$. fumigatus $(7,7 \%)$, sendo que os autores isolaram também em menor quantidade $(6,6 \%)$ A nidulans e $A$. terreus ${ }^{19}$.

Já nos EUA, Cooley et al. ${ }^{20}$, em estudo da qualidade do ar de escolas encontraram somente três espécies de Aspergillus, A. flavus, A. glaucus e A. versicolor, diferindo consideravelmente do ambiente avaliado no CRAM, onde foram isoladas sete diferentes espécies com predominância de $A$. fumigatus que não foi isolada em nenhuma colheita realizada nas escolas pelos referidos autores. Em um amplo trabalho de Shelton et al. ${ }^{21}$ quanto à presença de fungos anemófilos em 1.717 prédios, incluindo escolas, hospitais, residências e indústrias, resultados similares foram encontrados em relação a algumas espécies como $A$. fumigatus, $A$. niger e $A$. flavus, porém os autores encontraram $A$. versicolor como espécie predominante, isolada em alta freqüência, distinguindo das colheitas realizadas no CRAM.

Estas diferenças podem ser explicadas pelo tipo de ambiente estudado, bem como pelas variações geográficas e regionais que estão diretamente relacionadas à concentração fúngica nos ambientes internos ${ }^{21}$, a qual pode ainda ser influenciada por fatores climáticos e sazonais. ${ }^{15,16}$ Outros trabalhos semelhantes, de fungos anemófilos em centros de reabilitação, zoológicos ou aviários não foram encontrados na literatura, por isso os dados do presente estudo foram confrontados com resultados descritos em distintos ambientes internos, apesar da grande diferença entre estes locais, principalmente no que se refere à presença de matéria orgânica.

A espécie com maior percentual de isolamento foi $A$. fumigatus, cuja importância está relacionada à sua alta patogenicidade. Esta espécie é considerada o principal agente etiológico da aspergilose, responsável por 90 a 95\% dos casos clínicos, e frequentemente relacionada à alta mortalidade de pingüins e

Tabela 1 - Espécies de Aspergillus isoladas do ar das instalações de um Centro de Recuperação de Animais Marinhos (CRAM, Rio Grande, RS, Brasil), em um período de aproximadamente dois anos.

\begin{tabular}{|c|c|c|c|}
\hline N (\%) & Subgênero & Seção & Espécie \\
\hline $12(27,9)$ & Fumigati & Fumigati & A. fumigatus \\
\hline $\begin{array}{c}11(25,6) \\
7(16,3) \\
4(9,3)\end{array}$ & Circumdati & $\begin{array}{c}\text { Nigri } \\
\text { Flavi } \\
\text { Circumdati }\end{array}$ & $\begin{array}{l}\text { A. niger } \\
\text { A. flavus } \\
\text { A. candidus }\end{array}$ \\
\hline $\begin{array}{l}3(6,9) \\
3(6,9)\end{array}$ & Nidulantes & $\begin{array}{c}\text { Terrei } \\
\text { Versicolores }\end{array}$ & $\begin{array}{l}\text { A. terreus } \\
\text { A. versicolor }\end{array}$ \\
\hline $3(6,9)$ & Aspergillus & Aspergillus & E. chevalieri \\
\hline
\end{tabular}


outras aves marinhas em cativeiro. 4, 8, 10, 12, 22, 23 Dentre os fatores de patogenicidade do $A$. fumigatus pode-se destacar a termotolerância, a velocidade de crescimento, o pequeno diâmetro de seus conídios, e a produção de enzimas e toxinas. Todas estas características facilitam a penetração e o desenvolvimento fúngico no organismo do hospedeiro, que desencadeiam a aspergilose. ${ }^{22}$

Os estudos da qualidade do ar vêm sendo realizados com o intuito de contribuir com a saúde dos indivíduos à medida que fornecem dados sobre comportamento, sobrevivência e distribuição dos microrganismos fúngicos no ambiente. Tendo em vista que estes microrganismos anemófilos são constantemente inalados e podem causar danos à saúde, desde uma leve alergia respiratória a uma doença grave e invasiva, os resultados colaboram para elaboração de medidas de prevenção por fornecer dados sobre as possíveis fontes de contaminação e a presença de determinados fungos nas instalações. ${ }^{18,19,20,22}$

\section{Conclusão}

A presença de fungos do gênero Aspergillus no local de reabilitação de animais marinhos, com predominância de $A$. fumigatus, fundamenta a necessidade de um controle microbiológico no ambiente à medida que grande parte dos animais em reabilitação encontra-se imunossuprimida, podendo desenvolver a aspergilose pela inalação dos conídios anemófilos.

\section{Agradecimentos}

À Dra. Aurea Maria Lage de Moraes, Pesquisadora do Departamento de Micologia da Fundação Oswaldo Cruz (Instituto Oswaldo Cruz), pelo auxílio na identificação das espécies de Aspergillus.

\title{
Air contamination with Aspergillus species at an indoor rehabilitation centre for sea animals
}

\begin{abstract}
Aspergillosis in captivity seabirds is often associated with elevated rates of mortality. The infection is usually acquired by inhalation of airborne fungal conidia. The aim of this study was to evaluate the presence of Aspergillus species in the indoor environment of a rehabilitation centre for marine animals in Southern Brazil. This centre continuously receives injured penguins, seagulls, albatrosses and petrels. Petri dishes plates with Agar Sabouraud dextrose and chloramphenicol were left open for 15 minutes in 3 distinct points in the rehabilitation centre and then incubated at $25^{\circ} \mathrm{C}$. During a period of two years the indoor air was sampled in 81 occasions. A total of 43 isolates belonging to 7 different Aspergillus species were recovered. Aspegillus fumigatus was the predominant species (27.9\%), followed by $A$. niger $(25.6 \%)$, and $A$. flavus (16.3\%). Four other Aspergillus species were isolated. This study demonstrates that seabirds were exposed to pathogenic Aspergillus species in our rehabilitation centre, reinforcing the need for a strict microbiology control of the indoor air in the captivity environment.
\end{abstract}

Key words:

Air.

\section{Referências}

1 ABARCA, M. L. Taxonomía e identificación de especies implicadas en la Aspergilosis nosocomial.
Revista Iberoamericana de Micologia, v. 17, p. 79-84, 2000.

$2 \mathrm{KLICH}, \mathrm{M}$. A. Identification of common Aspergillus species. Utrecht: Centraalbureau voor Schimmelcultures, 
2002. 116 p.

3 RAPER, K. B.; FENNELL, D. I. The genus Aspergillus. Baltimore: Williams and Wilkins, 1965. p. 686.

4 AINSWORTH, G. C.; REWELL, R. E. The incidence of aspergillosis in captive wild birds. Journal of Comparative Pathology and Therapeutics, v. 59, p. 213-224, 1949.

5 BRETAGNE, S. et al. Fatal primary coetaneous aspergillus's in a boné marrow transplant recipient: nosocomial acquisition in a laminar-air flow room. Journal of Hospital Infection, v. 36, n. 3, p. 235-239, 1997.

6 CORK, S. C. et al. Aspergillosis and other causes of mortality in the Stitchbird in New Zealand. Journal of Wildlife Diseases, v. 35, n. 3, p. 481-486, 1999.

7 FLACH, E. J.; STEVENSON, M. F.; HENDERSON, G. M. Aspergillosis in gentoo penguins (Pygoscelis papua) at Edinburgh Zoo, 1964-1988. Veterinary Record, v. 126, n. 4, p. 81-85, 1990.

$8 \mathrm{KHAN}, \mathrm{Z}$. U. et al. Aspergillosis in imported penguins. Sabouraudia, v. 15, p. 43-45, 1977.

9 LAIR-FULLERINGER, S. et al. Differentiation between Isolates of Aspergillus fumigatus from Breeding Turkeys and Their Environment by Genotyping with Microsatellite Markers. Journal of Clinical Microbiology, v. 41, n. 4, p. 1798-1800, 2003.

10 MARTINÉZ, R. R.; CERECERO, J.; CERVANTES, J. Brote de aspergilosis em gaviotas. Veterinaria Mexico, v. 31, n. 3, p. 259-260, 2000.

11 TELL, L. A. Aspergillosis in mammals and birds: impact on veterinary medicine. Medical Mycology, v. 43, p. 71-73, 2005, Supplement 1.

12 CARRASCO, L. et al. Systemic aspergillosis in an oiled magallanic Penguin (Spheniscus magellanicus). Journal of Veterinary Medicine, v. 48, p. 551-554, 2001.

13 RUSSEL, M.; HOLCOMB, J.; BERKNER, A. 30-years of oiled wildlife responses statistics. In: INTERNATIONAL EFFECTS OF OIL AND WILDLIFE
CONFERENCE, 7., 2003, Hamburg, Germany. Proceedings... p. 1-18.

14 GIGLI, A. C. S. et al. Diagnosis and evaluation of fungi presence in the air of two different ventilation systems for broiler houses. Brazilian Journal of Poultry Science, v. 7, n. 4, p. 205-208, 2005.

$15 \mathrm{LEE}, \mathrm{T}$. et al. Relationship between indoor and outdoor bioaerosols collected with a button inhalable aerosol sampler in urban homes. Indoor Air, v. 16, p. 37-47, 2006.

16 REN, P. et al. The relation between fungal propagules in indoor air and home characteristics. Allergy, v. 56, p. 419-424, 2001.

17 WU, P. C.; LI, Y. Y.; CHIANG, C. M. et al. Changing microbial concentrations are associated with ventilation performance in Taiwan's air-conditioned office buildings. Indoor Air, v. 15, n. 1, p. 19-26, 2005.

18 LEENDERS, A. C. A. P. et al. Density and molecular epidemiology of Aspergillus in air and relationship to outbreaks of Aspergillus infection. Journal of Clinical Microbiology, v. 37, n. 6, p. 1752-1757, 1999.

19 PANAGOPOULOU, P. et al. Environmental surveillance of filamentous fungi in three tertiary care hospitals in Greece. Journal of Hospital Infection, v. 52, p. 185-191, 2002.

20 COOLEY, J. D. et al. Correlation between the prevalence of certain fungi and sick building syndrome. Occupational and Environmental Medicine, v. 55, p. 579-584, 1998.

21 SHELTON, B. G. et al. Profiles of airborne fungi in buildings and outdoor environments in the United States. Applied and Environmental Microbiology, v. 68, n. 4, p. 1743-1753, 2002.

22 LATGÉ, J. P. Aspergillus fumigatus and Aspergillosis. Clinical Microbiology Reviews, v. 12, n. 2, p. 310-350, 1999.

23 XAVIER, M. O. et al. Aspergilose em Pingüim-demagalhães (Spheniscus magellanicus) - Relato de Caso. Veterinária e Zootecnia, v. 13, n. 1, p. 28-32, 2006. 